\title{
Treatment of stable COPD: antioxidants
}

\author{
W. MacNee
}

ABSTRACT: There is considerable evidence that an increased oxidative burden occurs in the lungs of patients with chronic obstructive pulmonary disease (COPD) and this results in an imbalance between oxidants/antioxidants or oxidative stress, which may play a role in many of the processes involved in the pathogenesis of COPD. These include enhanced proteolytic activity, mucus hypersecretion and the enhanced inflammatory response in the lungs to inhaling tobacco smoke, which is characteristic of COPD. COPD is now recognised to have multiple systemic consequences, such as weight loss and skeletal muscle dysfunction. It is now thought that oxidative stress may extend beyond the lungs and is involved in these systemic effects.

Antioxidant therapy therefore would seem to be a logical therapeutic approach in chronic obstructive pulmonary disease. There is a need for more potent antioxidant therapies to test the hypothesis that antioxidant drugs may be a new therapeutic strategy for the prevention and treatment of chronic obstructive pulmonary disease.

\section{KEYWORDS: Antioxidants, chronic obstructive pulmonary disease, oxidative stress}

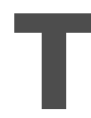
he lungs are continuously exposed to oxidants generated either endogenously (e.g. released from phagocytes or intracellular oxidants, e.g. from mitochondrial electron transport) or exogenously (e.g. air pollutants or cigarette smoke). The lungs are protected against this oxidative challenge by well-developed enzymatic and nonenzymatic antioxidant systems. Oxidative stress is said to occur when the balance between oxidants and antioxidants shifts in favour of oxidants, from either an excess of oxidants and/or depletion of antioxidants (fig. 1) [1].

Smoking is the main aetiological factor in chronic obstructive pulmonary disease (COPD). Cigarette smoke contains $10^{17}$ oxidant molecules per puff, and this, together with a large body of evidence demonstrating increased oxidative stress in smokers and in patients with COPD, has led to the proposal that an oxidant/antioxidant imbalance is important in the pathogenesis of this condition [2]. Oxidative stress not only produces direct injurious effects in the lungs, but also activates the molecular mechanisms that initiate lung inflammation [3] and may have a role in many of the processes thought to be involved in the complex pathological events that result in COPD.

Increasingly, COPD is recognised not only to affect the lungs, but to have significant systemic consequences, such as muscle dysfunction and weight loss [4]. Oxidative stress is also thought to play an important role in this aspect of the disease [5].

\section{EVIDENCE OF OXIDATIVE STRESS IN THE LUNGS}

Oxidative stress can be measured in several different ways, either as direct measurements of the oxidative burden, as the responses to oxidative stress or the effect of oxidative stress on target molecules. Numerous studies using various techniques have now shown that oxidative stress is increased in the lungs of COPD patients compared with healthy subjects, but also compared with smokers with similar smoking history, but who have not developed COPD [2].

\section{INCREASED OXIDANT BURDEN IN COPD}

Reactive oxygen (ROS) and reactive nitrogen species, in addition to other molecules, such as protein radicals and lipid peroxidation products, contribute to the oxidant/antioxidant imbalance seen in COPD. ROS are produced by the sequential reduction of oxygen. The addition of one electron to oxygen produces super oxide anion $\left(\mathrm{O}_{2}^{-}\right)$, the addition of a second electron results in hydrogen peroxide $\left(\mathrm{H}_{2} \mathrm{O}_{2}\right)$ and a third yields the formation of hydroxyl radical $(\mathrm{OH} \cdot)$. These intermediates are called ROS and react readily with molecules such as proteins, lipids and DNA (fig. 2). The addition of a fourth electron produces the complete reduction of $\mathrm{O}_{2}^{-}$ to water, which no longer reacts with other molecules. A free radical is a molecule with at least one unpaired electron, such as the superoxide hydroxyl radical and nitric oxide (NO)

Cigarette smoke contains $>5,000$ different chemicals of which many are oxidants, including
CORRESPONDENCE

W. MacNee

ELEGI

Colt Research Laboratories

Wilkie Building

Medical School

Teviot Place

Edinburgh EH8 9AG

Scotland

Fax: 441316511558

E-mail: w.macnee@ed.ac.uk 
a)

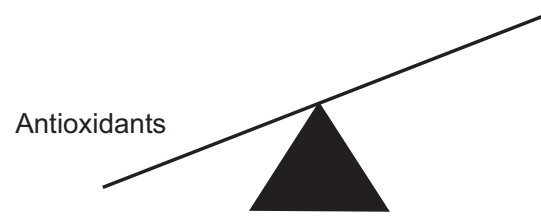

b)

Antioxidants

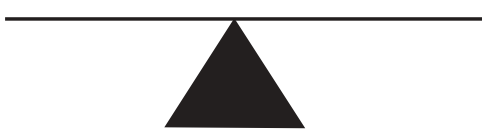

c)

Antioxidants

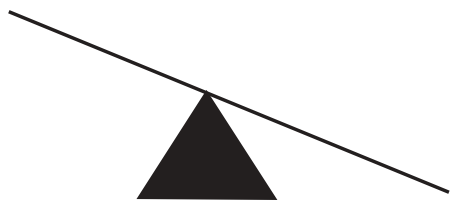

Reactive oxygen species

FIGURE 1. Oxidative stress is an imbalance between reactive oxygen species (ROS) and antioxidants. a) Under normal conditions there are sufficient antioxidants in the lung to overcome endogenous ROS. b) During pathologic states there is an increase in ROS that may be balanced by increase in antioxidants. c) When either ROS production is excessive or antioxidants are inadequate, the balance is tipped toward oxidative stress and injury from ROS may occur.

$\mathrm{H}_{2} \mathrm{O}_{2}, \mathrm{O}_{2}{ }^{-}, \mathrm{OH} \cdot$ and $\mathrm{NO}$ [5-7]. Cigarette smoke can be separated into a gas and a particulate phase (tar phase) and both of these contain abundant oxidants. The gas phase is less stable and is estimated to contain $>10^{15}$ free radicals per puff. The tar phase by contrast is more stable and is estimated to contain $>10^{17}$ free radicals per gram [7]. Iron is present in

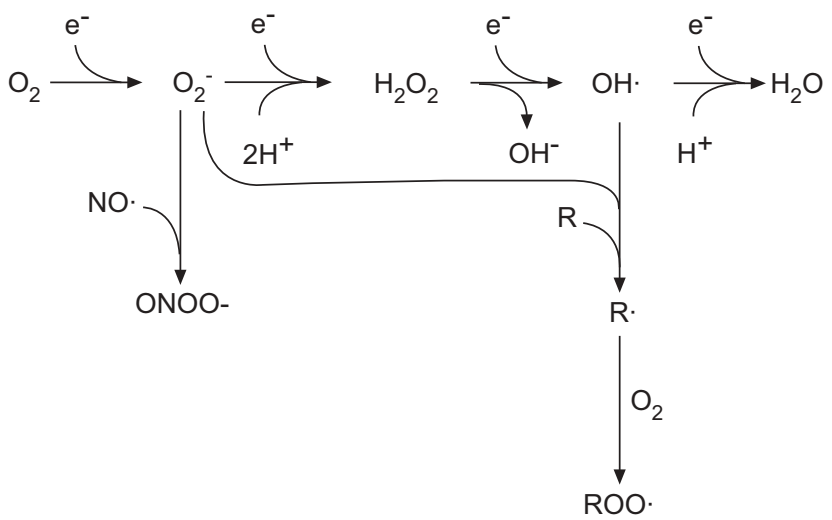

FIGURE 2. Production of reactive oxygen species. Sequential addition of electrons $\left(e^{-}\right)$to oxygen results in the formation of reactive oxygen species (superoxide anion $\left(\mathrm{O}_{2}{ }^{-}\right)$, hydrogen peroxide $\left(\mathrm{H}_{2} \mathrm{O}_{2}\right)$ and hydroxyl radical $(\mathrm{OH} \cdot) . \mathrm{O}_{2}$ can combine with nitric oxide (NO-) to form peroxynitrite (ONOO-). Both $\mathrm{O}_{2}^{-}$and $\mathrm{OH}^{-}$can initiate lipid peroxidation to form lipid peroxides (ROO·) that can propagate free radical chain reactions. cigarette smoke and in the epithelial lining fluid and may catalyse the production of free radicals through the Fenton and Haber-Weiss reactions. Air pollutants are another exogenous source of reactive oxygen species in the lungs [8]. The lung is exposed to oxidants from the environment; however, a large proportion of oxidants produced endogenously in the lungs are by-products of normal cellular metabolism. Mitochondria are the largest source of free radicals, as a result of electron leak from the electron transport chain onto oxygen to form superoxide [7]. Xanthine/xanthine oxidase is another significant cytosolic source of superoxide [9]. Membrane oxidases, such as cytochrome P450 enzymes [10] and the nicotinamide adenine dinucleotide phosphate (NADPH) oxidases, also produce substantial quantities of superoxide. Reactive nitrogen species are derived from NO, which is produced by the three $\mathrm{NO}$ synthases. $\mathrm{NO}$ is produced in high concentrations as a result of inducible $\mathrm{NO}$ activation and can react with oxygen or superoxide to form $\mathrm{NO}$ and peroxinitrite. $\mathrm{NO}$ can also react with thiols to produce nitrosothiols and can metabolise to nitrite.

\section{ANTIOXIDANTS IN THE LUNGS}

Antioxidants are usually classified as either enzymatic or nonenzymatic and are the primary defences against reactive oxygen/reactive nitrogen species (fig. 3). Antioxidant enzymes include the superoxide dismutase (SOD) family, catalase, glutathione (GSH) peroxidase, GSH S-transferase and thioredoxin [11].

The nonenzymatic antioxidants include low molecular weight compounds, such as GSH, ascorbate, urate, alpha-tocopherol, bilirubin and lipoic acid. Concentrations of these nonenzymatic antioxidants vary in the lungs. Some, for example GSH, are more concentrated in epithelial lining fluid compared with plasma [12] and others, such as albumin, are found in high concentration in serum, but at much lower concentrations in the epithelial lining fluid (table 1) [13].

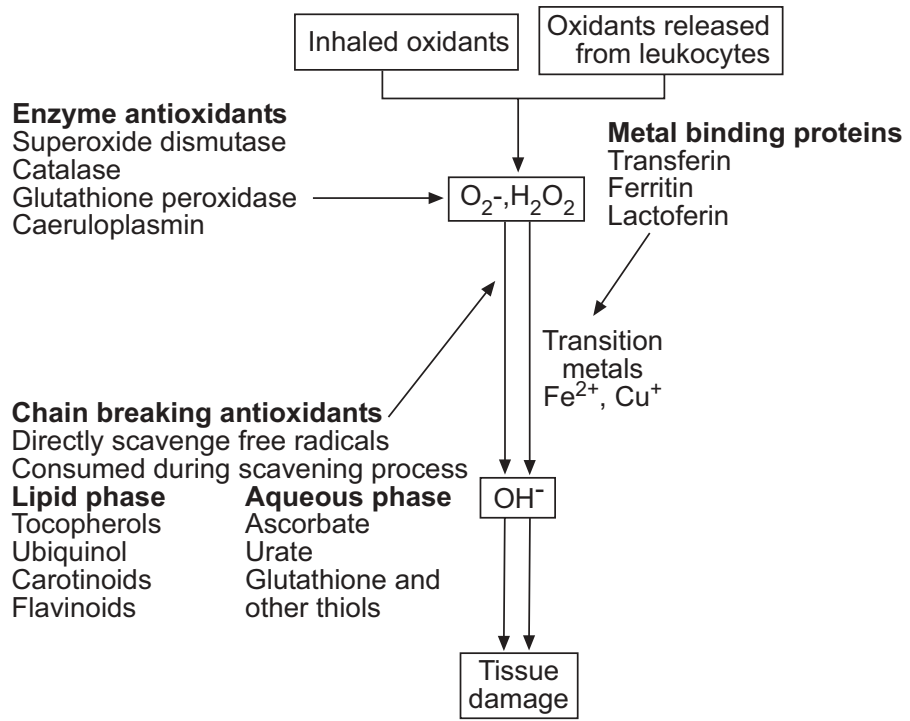

FIGURE 3. Antioxidant systems in the lungs. $\mathrm{O}_{2}{ }^{-}$: superoxide anion; $\mathrm{H}_{2} \mathrm{O}_{2}$ : hydrogen peroxide; $\mathrm{OH}^{-}$: hydroxyl. 


\begin{tabular}{lcc}
\hline TABLE 1 & $\begin{array}{l}\text { Low molecular weight antioxidants in normal } \\
\text { subjects }\end{array}$ \\
\hline Antioxidant & Plasma & Epithelial lining fluid \\
\hline Glutathione & $1.0 \pm 0.7$ & $109 \pm 64$ \\
Urate & $378 \pm 133$ & $207 \pm 167$ \\
Ascorbate (Vitamin C) & $67 \pm 25$ & $40 \pm 18$ \\
$\boldsymbol{\alpha}$-tocopherol (Vitamin $\mathrm{E})$ & $16 \pm 5$ & $0.7 \pm 0.3$ \\
\hline \multicolumn{3}{l}{ Data presented as mean $\pm \mathrm{SD}$, in $\mu \mathrm{M}$. }
\end{tabular}

\section{ANTIOXIDANT ENZYMES}

\section{Superoxide dismutase family}

The superoxide dismutase family are major antioxidant enzymes in the lungs. These enzymes catalyse the dismutation of superoxide radicals to $\mathrm{H}_{2} \mathrm{O}_{2}$ and oxygen. Three SOD isoenzymes have been identified in mammals. The major intracellular SOD is the copper/zinc SOD $(\mathrm{Cu} / \mathrm{Zn}$ SOD or SOD1) [14]. The mitochondrial SOD is manganese SOD (Mn SOD or SOD2), which is synthesised in the cytoplasm and translocated to the mitochondria $[15,16]$. A third member of the SOD family is primarily extracellular (EC SOD or SOD3) [17].

$\mathrm{Cu} / \mathrm{Zn} \mathrm{SOD}$ is the most abundant superoxide dismutase in most tissues. It is highly expressed in bronchial and alveolar epithelial cells and in mesenchymal cells, fibroblasts, arterioles and endothelial cells $[18,19]$. $\mathrm{Cu} / \mathrm{Zn}$ SOD is primarily located in the cytosol and in the nucleus of cells.

Mn SOD is found in arterial walls adjacent to airways [20, 21] and is exclusively localised in the mitochondria [18].

Extracellular SOD mRNA is abundant in airway epithelium and vascular endothelium in the lungs.

\section{The thioredoxin system}

This system consists of multiple species, including the thioredoxins, thioredoxin-like proteins and the thioredoxin reductases [22-24]. These enzymes are important in protein disulfide reduction.

\section{The glutathione redox system}

GSH is the most abundant intracellular thiol-based antioxidant. It is concentrated in the epithelial lining fluid and plays a critical role in maintaining intracellular redox status, in addition to detoxifying compounds via conjugation reactions through GSH S transferase. Bronchoalveolar lavage fluid (BALF) contains 100-fold concentration of GSH compared with the blood $[12,25]$. GSH is also highly concentrated in intracellular spaces [7].

\section{OXIDATIVE STRESS IN COPD}

There is now considerable evidence showing the presence of increased oxidative stress in COPD. Direct measurements of the airspace oxidative burden, such as measurements of $\mathrm{H}_{2} \mathrm{O}_{2}$ in exhaled breath condensate, thought to derive from increased release of $\mathrm{O}_{2}^{-}$by alveolar macrophages [26], show higher levels in smokers and patients with COPD, than in ex-smokers with COPD, or nonsmokers [27, 28] (fig. 4). $\mathrm{O}_{2}{ }^{-}$and $\mathrm{H}_{2} \mathrm{O}_{2}$ are also

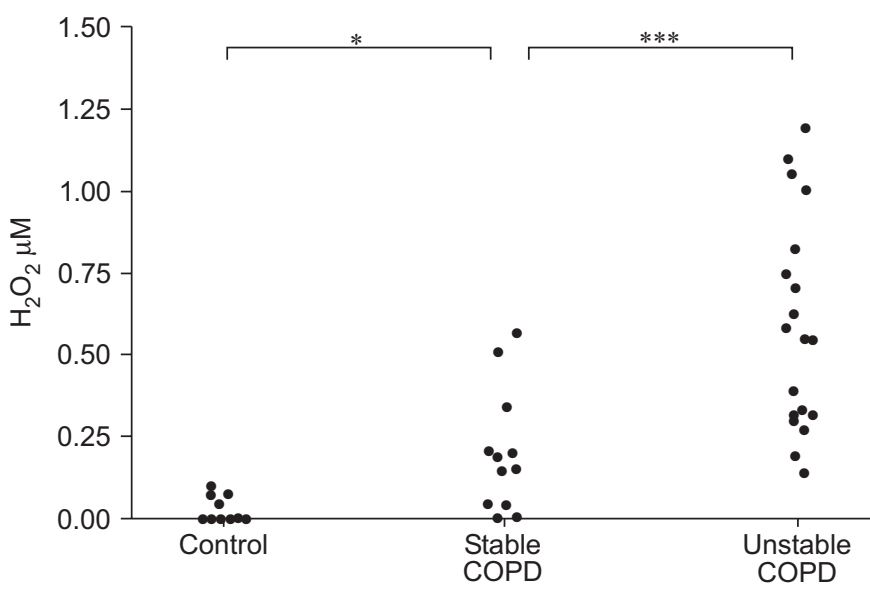

FIGURE 4. Hydrogen peroxide $\left(\mathrm{H}_{2} \mathrm{O}_{2}\right)$ levels in exhaled breath condensate in clinically stable and unstable chronic obstructive pulmonary disease (COPD) patients. ${ }^{*}: \mathrm{p}<0.05$; ${ }^{* * *}: \mathrm{p}<0.001$. Reproduced with permission [27].

derived from the xanthine/xanthine oxidase reaction, which shows increased activity in BALF and in the plasma of smokers and in patients with COPD, compared with healthy subjects and nonsmoking subjects $[29,30]$.

NO has been used as a marker of airway inflammation and indirectly as a measure of oxidative stress. It's rapid reactivity with $\mathrm{O}_{2}^{-}$or with thiols may alter $\mathrm{NO}$ levels in breath and, as a result, increased levels of $\mathrm{NO}$ in exhaled breath occur in some [31-33], but not in other studies of patients with COPD [34, 35].

However, nitrosothiols have been shown to be higher in breath condensate in smokers and COPD patients, compared to nonsmoking subjects (fig. 5) [36]. In addition, peroxynitrite, formed by the reaction of $\mathrm{NO}$ with $\mathrm{O}_{2}{ }^{-}$, can cause nitration of tyrosine to produce nitrotyrosine [37]. Nitrotyrosine levels are elevated in sputum leukocytes of COPD patients and are negatively correlated with forced expiratory volume in one second (FEV1) [38].

Exhaled carbon monoxide $(\mathrm{CO})$ as a measure of the response of Haem oxygenase to oxidative stress has been shown to be elevated in exhaled breath in $\mathrm{CO}$ compared with normal subjects [39].

Lipid peroxidation products, such as thiobarbituric acidreacting substances and malondealdehyde, are elevated in sputum in patients with COPD and are negatively correlated with the FEV1 [40-42].

Isoprostanes, produced by ROS-mediated peroxidation of arachidonic acid, are found in higher levels in breath condensate in patients with COPD, compared with normal subjects and smokers who have not developed the disease and have also been shown to correlate with the degree of airways obstruction [43]. The levels of 8-isoprostane in breath condensate in COPD patients also show a positive correlation with the percentage neutrophils in induced sputum, suggesting oxidative stress may be involved in the airway inflammation in COPD (fig. 6) [44]. Increased levels of isoprostanes in plasma in smokers [45] and in urine in COPD patients [46] reflect systemic oxidative stress. 

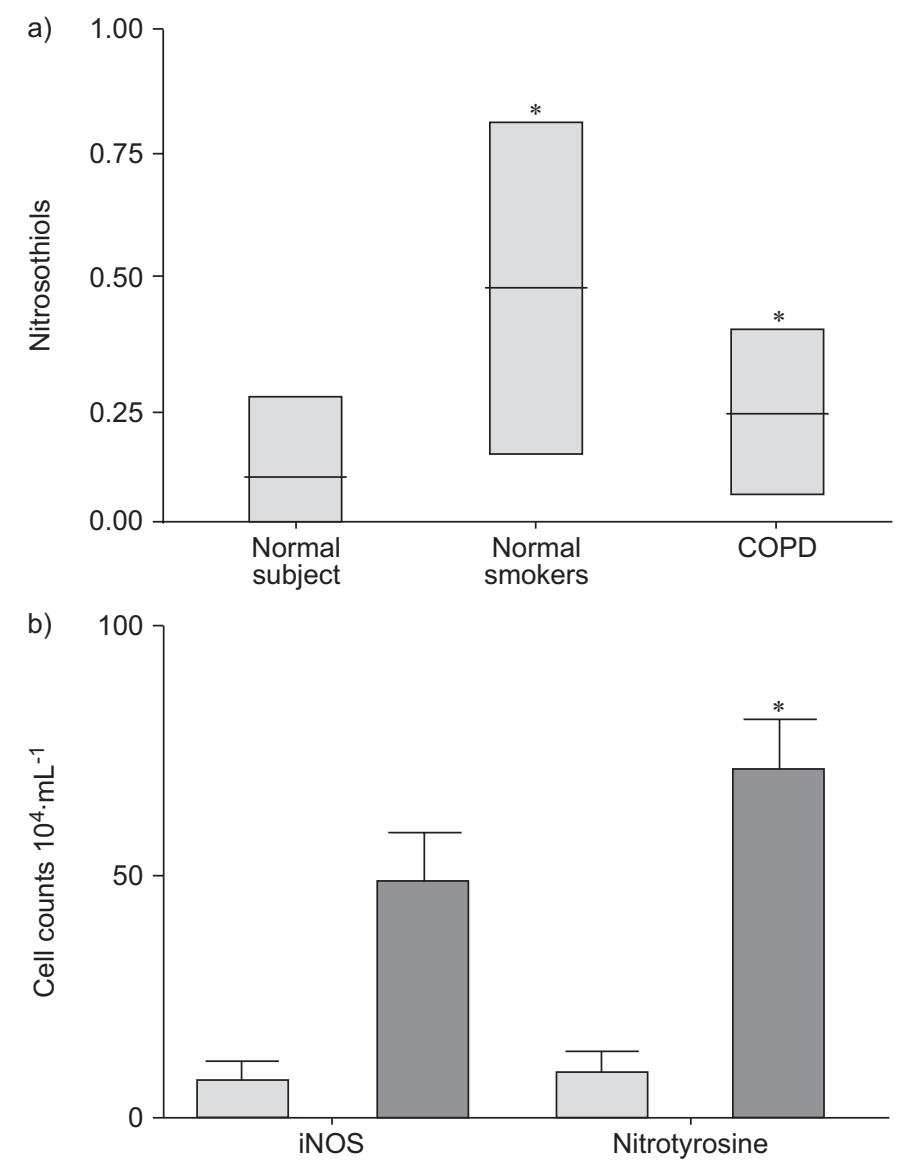

FIGURE 5. a) Levels of nitrosothiols in breath condensate in normal healthy smokers and patients with chronic obstructive pulmonary disease (COPD). b) Increased inducible nitric oxide (iNOS) and nitrotyrosine immunoreactivity in sputum leukocytes in COPD $(\square)$ and healthy subjects $(\square)$. * $p<0.05$ compared with normal nonsmoking subjects.

Hydrocarbon gases are by-products of ROS peroxidation of fatty acids [39]. Increased levels of exhaled breath ethane occur in COPD patients compared with control subjects, and the levels are negatively correlated with lung function [47].

Increased markers of oxidative stress are also present in lung cells in COPD patients. Increased nitrotyrosine has been shown in sputum leukocytes in COPD patients and lung tissue compared with healthy subjects (fig. 5b) [38]. The lipid peroxidation product, 4-hydroxynonenal, reacts quickly with cellular proteins to form adducts, which are present in greater quantities in airway epithelial and endothelial cells in the lungs of COPD patients, compared with smokers with a similar smoking history who have not developed the disease (fig. 7) [48].

Thus there is considerable evidence of increased markers of oxidative stress in the airways and in lung tissue in COPD patients, compared with normal subjects and smokers who have not developed the disease. In addition, many of these markers of oxidative stress correlate with the degree of airflow limitation in COPD, suggesting a role for oxidative stress in the decline in lung function in COPD.
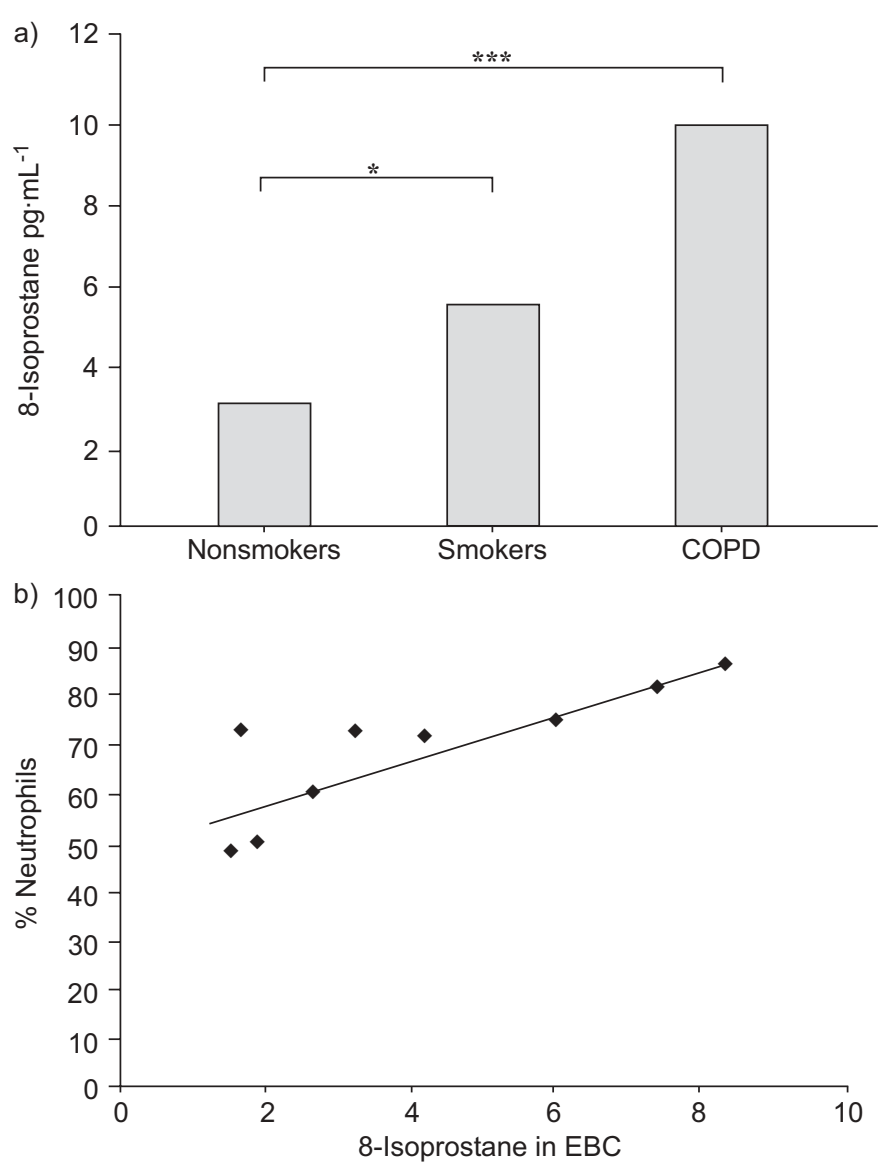

FIGURE 6. a) 8-isoprostane levels in exhaled breath condensate in smokers with chronic obstructive pulmonary disease (COPD). *: $p<0.05$; $* * *: p<0.001$. b) There is a significant correlation between 8-isoprostane levels in exhaled breath condensate $(E B C)$ and the percentage of neutrophils in induced sputum. $p<0.001$ $r=0.81$.

\section{SYSTEMIC OXIDATIVE STRESS}

An increased systemic oxidative burden has been shown to occur in smokers. In COPD peripheral blood neutrophils have been shown to release more reactive oxygen species than in normal subjects and this is enhanced still further in exacerbations of the disease, and is associated with marked depletion of the plasma antioxidant capacity, indicating increased systemic oxidative stress (fig. 8) [49]. Products of lipid peroxidation are also increased in plasma in smokers with COPD, particularly during exacerbations [49]. Increased levels of nitrotyrosine have also been shown to occur in the plasma of COPD patients [37].

Exacerbations of COPD are known to result from increased levels of air pollutants, specifically particulate air pollution [8]. Particulate air pollution causes oxidative stress in the airways [50] and enhanced inflammation by similar mechanisms to those described for cigarette smoke, through oxidative stressinduced transcription factor activation.

It is now recognised that COPD is not only a disease which affects the lungs, but has important systemic consequences, such as cahexia and skeletal muscle dysfunction [51]. Increasing evidence of similar mechanisms involving oxidative 

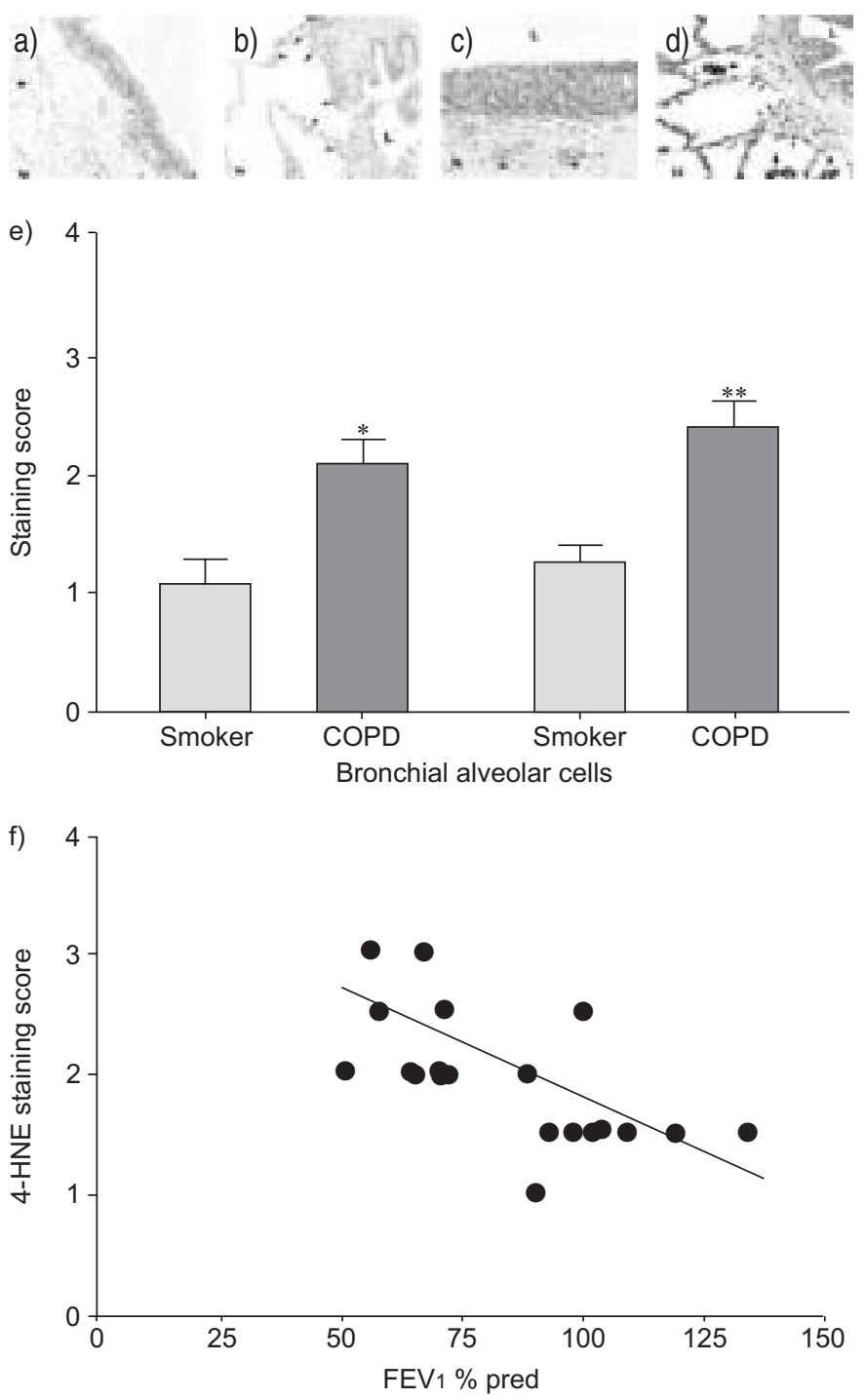

FIGURE 7. Immunostaining for lipid peroxidation product 4-hydroxy-2-nonenal (4-HNE) adduct in the lungs of smokers with and without chronic obstructive pulmonary disease (COPD). Immunohistochemistry showing increased staining in both bronchial and alveolar epithelium in smokers without $(a, b)$ and with (c, d) COPD. e) 4-HNE staining score showing increased staining in COPD. *: $p<0.05$; $* *: p<0.01$. f) Correlation between 4-HNE staining score in the lungs and per cent predicted forced expiratory volume in one second ( $\left.F E V_{1}\right)$. $R=-0.76 ; p<0.05$. Reproduced with permission [48].

stress and inflammation in the lungs may also be responsible for many of the systemic effects of COPD [5, 52].

\section{ANTIOXIDANTS IN COPD}

A relationship between dietary antioxidants, pulmonary function and the development of COPD has been shown in several population studies. The American Nutrition Examination Survey (NHANES) and the Dutch monitoring project for the risk factors for chronic diseases (MORGAN) have shown relationships between antioxidant dietary intake and airflow limitation. In NHANES (I) lower dietary intake of vitamin $C$ was related to lower FEV1 levels in a population survey [53]; data from NHANES (II) showed an inverse
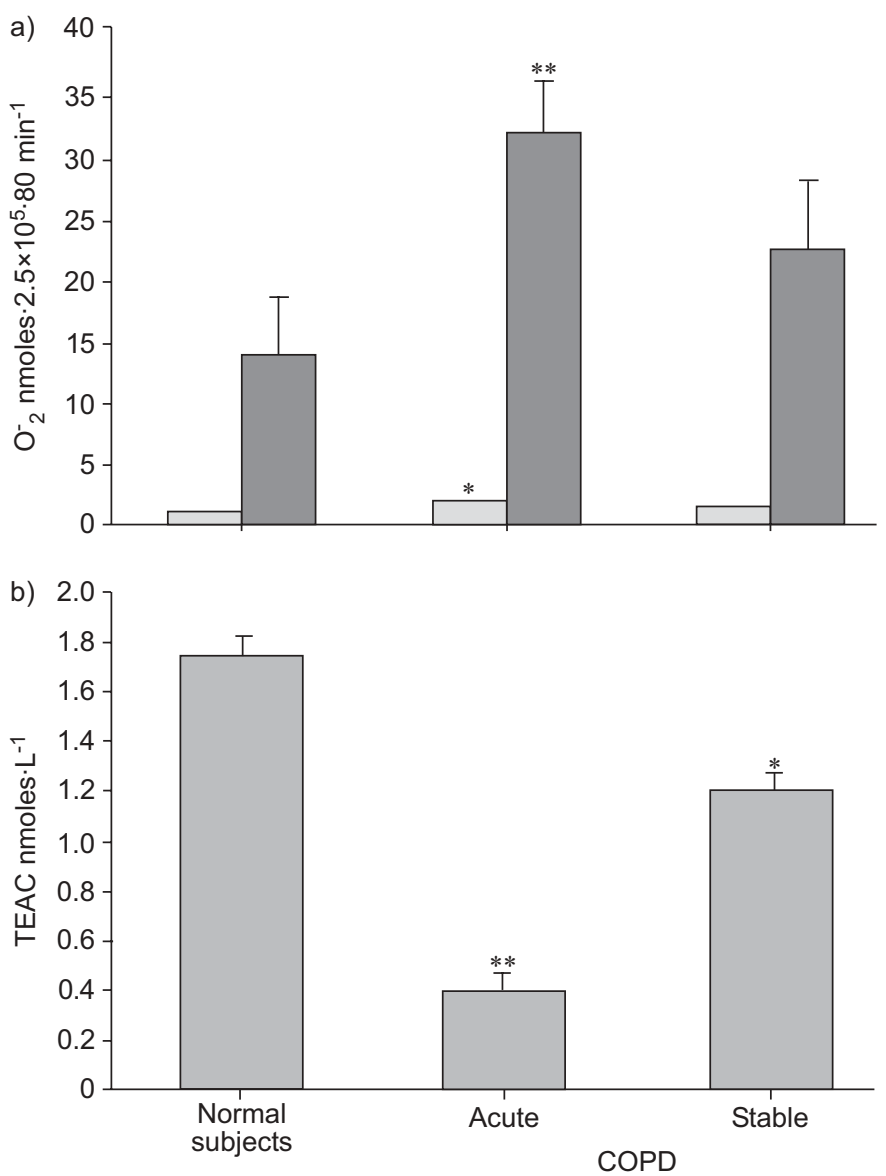

FIGURE 8. Oxidative stress in exacerbations of chronic obstructive pulmonary disease (COPD). a) Superoxide $\left(\mathrm{O}_{2} \cdot\right)$ anion release from peripheral blood neutrophils (spontaneous $(\square)$ and phorbol myristate acetate $(\square)$ activated) in normal subjects and in acute and stable COPD. b) Plasma antioxidant capacity (Trolox Equivalent Antioxidant Capacity (TEAC)) in normal subjects and in acute and stable COPD. *: $p<0.05 ;{ }^{*}: p<0.01$.

relationship between both dietary and serum vitamin $C$ and chronic respiratory symptoms [54] and in NHANES (III) the levels of dietary vitamin $C$, vitamin $E$, selenium and betacarotene correlated positively with lung function [55]. Similarly the MORGAN study has also shown that a higher intake of vitamin $C$ and beta-carotene was associated with higher levels of the FEV1. This and other studies have shown associations between fruit intake and higher FEV1 and lower symptoms in COPD patients [56-59].

As a response to oxidative stress induced by cigarette smoke, there appears to be upregulation of protective antioxidant genes in the lungs. The antioxidant GSH is elevated in the epithelial lining fluid in chronic cigarette smokers, compared with nonsmokers, an increase that does not occur during acute cigarette smoking [52]. The effects of chronic cigarette smoking can be mimicked by exposure of airspace epithelial cells to cigarette smoke condensate in vitro. This produces an initial decrease in intracellular GSH, with a rebound increase after $24 \mathrm{~h}[60,61]$. This effect in vitro is mimicked by a similar change in GSH in rat lungs in vivo following exposure to 
cigarette smoke [61], associated with an increase in the oxidised form of GSH. The increase in GSH following cigarette smoke exposure is due to transcriptional upregulation of mRNA for $\gamma$-glutamylcysteine synthetase, the rate-limiting enzyme in GSH synthesis [61]. The mechanism of the upregulation of $\gamma$-glutamylcysteine synthetase mRNA is through the activation by cigarette smoke of the redoxsensitive transcription factor activator protein-1 (AP-1) [62, 63]. These events are likely to account for the increased levels seen in epithelial lining fluid in chronic cigarette smokers, which acts as a protective mechanism. The injurious effects of cigarette smoke may occur repeatedly during and immediately after cigarette smoking when the lung is depleted of antioxidants, including GSH. Animals exposed to whole cigarette smoke for up to 14 days also show increased expression of a number of antioxidant genes including manganese superoxide dismutase, matallothionein and GSH peroxidase [21].

\section{OXIDATIVE STRESS AND THE PATHOGENESIS OF COPD}

Although studies have shown that oxidative stress is increased in COPD and is related to the development of airflow limitation, this does not indicate cause and effect, since oxidative stress may be an epi-phenomenon related to the presence of inflammation [64]. There are as yet no longitudinal studies showing that the presence of enhanced oxidative stress is related to the decline in FEV1, nor to the progression of the disease. However, there are many studies that indicate that oxidative stress is involved in most of the processes that are thought to be important in the pathogenesis of COPD.

A relative "deficiency" of antiproteases, such as alpha-1antitrypsin, due to their inactivation by oxidants, is thought to create a protease-antiprotease imbalance in the lungs, which forms the basis of the protease/antiprotease theory of the pathogenesis of emphysema [65, 66]. Although inactivation of alpha-1-antitrypsin by oxidants from cigarette smoke or oxidants released from inflammatory leukocytes has been shown in vitro $[67,68]$, the effect is less apparent in vivo [69]. However, a protease/antiprotease imbalance involving alpha1-antitrypsin and elastase is an oversimplification, since other proteases and other antiproteases are likely to have a role.

Oxidant generating systems, such as xanthine/xanthine oxidase, have been shown to cause the release of mucus from airway epithelium [70]. Oxidants are also involved in the signalling pathways for the epidermal growth factor receptor, which has an important role in the release of mucus [71]. Oxidants, such as $\mathrm{H}_{2} \mathrm{O}_{2}$ or hypochlorous acid, in low concentrations $(100 \mu \mathrm{M})$ have been shown to cause significant impairment of ciliary beating and even complete ciliary stasis [72]. Thus, oxidant-mediated mucus hypersecretion and impaired mucociliary clearance may result in the accumulation of mucus in the airways contributing to airflow limitation.

Injury to the airway epithelium is an important early event following exposure to cigarette smoke, as shown by an increase in airspace epithelial permeability. Increased epithelial permeability can be shown to result from cigarette smoke exposure both in vitro and in vivo $[52,73,74]$ and is partially reversible by antioxidants. Extra and intracellular GSH appears to be critical to the maintenance of epithelial integrity following exposure to cigarette smoke, since depletion of lung GSH alone can induce increased airspace epithelial permeability both in vitro and in vivo $[74,75]$. Interindividual variability in antioxidant defences may be one factor in determining whether COPD develops in cigarette smokers.

There is now overwhelming evidence that COPD is associated with enhanced airway and airspace inflammation, as is shown in recent biopsy studies [76]. Oxidative stress may be a mechanism by which airspace inflammation is enhanced in COPD [77]. Oxidative stress may have a fundamental role enhancing inflammation through the upregulation of redox sensitive transcription factors, such as nuclear factor- $\kappa \mathrm{B}$ (NF$\kappa \mathrm{B})$ and $\mathrm{AP}-1$, and also through the extracellular signalregulated kinase, jun-N-terminal kinase and p38 mitogen activated protein-kinase signalling pathways. Cigarette smoke has been shown to activate all of these signalling pathways [3, $78,79]$. Genes for many inflammatory mediators are regulated by oxidant sensitive transcription factors, such as NF- $\kappa \mathrm{B}[80$, 81]. In vitro studies, both in macrophage cell lines and, alveolar and bronchial epithelial cells, show that oxidants cause the release of inflammatory mediators, such as interleukin (IL)-8, IL-1, and NO, and that these events are associated with increased expression of the genes for these inflammatory mediators, and increased nuclear binding and activation of $\mathrm{NF}-\kappa \mathrm{B}[82,83]$. NF- $\mathrm{B}$ has been shown to be activated and translocated to the nucleus in lung tissue in smokers and in patients with COPD compared with healthy subjects [78, 84]. NF- $\kappa B$ activation in lung tissue has been shown to correlate with the FEV1 [85]. Linking of NF- $\kappa B$ to its consensus site in the nucleus leads to enhanced transcription of pro-inflammatory genes and hence inflammation, which itself will produce more oxidative stress, creating a vicious circle of enhanced inflammation resulting from the increased oxidative stress (fig. 9). Animal models of smoke exposure show that neutrophil influx in the lungs is associated with increased IL- 8 gene expression and protein release and with NF- $\kappa \mathrm{B}$ activation [86, 87]. All of these events are associated with oxidative stress since they can be abrogated by antioxidant therapy [86].

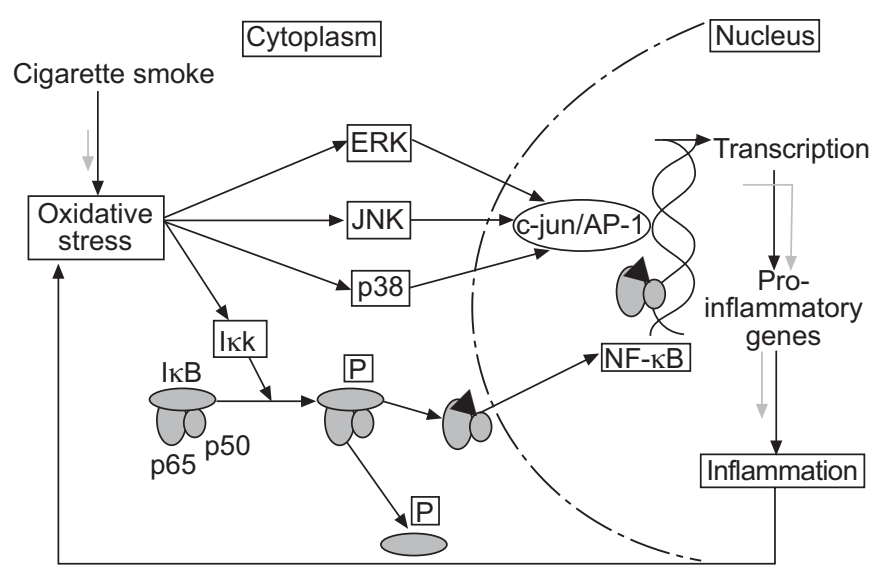

IKB degradation

FIGURE 9. Activation of cellular signal pathways by oxidative stress. ERK

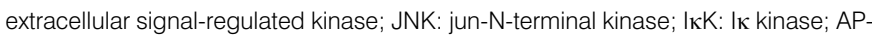

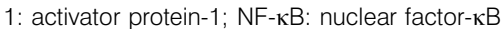


A further event induced by oxidative stress that may enhance the inflammation in the lungs is chromatin remodelling, which allows access for transcription factors, such as NF- $\kappa B$ and RNA polymerase to the transcriptional machinery, so enhancing gene expression. This process is known to be oxidant sensitive [77].

A recent hypothesis in the pathogenesis of emphysema is that loss of lung cells in alveolar walls, specifically endothelial cells, may occur as an initial event in the development of emphysema as a result of endothelial cell apoptosis [88]. Apoptosis has been shown to occur to a greater extent in emphysematous lungs than in nonsmokers' lungs [89]. The process of endothelial apoptosis is thought to be under the influence of the vascular endothelial growth factor receptor 2 (VEGF R2) (KDR) receptor. Downregulation of VEGF R2 has been shown in animal models to produce emphysema [89] and such downregulation of VEGF R2 has been shown to occur in emphysematous lungs [89]. Studies have also shown that the apoptosis/emphysema produced by VEGF inhibition in animal models is associated with increased markers of oxidative stress and is prevented by antioxidants [90], suggesting that oxidative stress is involved in this process but also in the systemic effects, such as muscle dysfunction in COPD [91].

\section{ANTIOXIDANT THERAPY}

Although there is now convincing evidence for an oxidant/ antioxidant imbalance in COPD, proof of concept of the role of oxidative stress in the pathogenesis of COPD will come from studies with effective antioxidant therapy.

Various approaches have been tried to redress the oxidant/ antioxidant imbalance. One approach is to give effective antiinflammatory therapy to reduce lung inflammation, which will in turn decrease oxidative stress. Possible therapeutic options for this are drugs to prevent leukocyte influx into the lungs, either by interfering with the adhesion molecules necessary for migration, or preventing the release of inflammatory cytokines, such as IL-8 or leukotriene B4, which result in neutrophil migration. It should also be possible to use agents to prevent the release of oxygen radicals from activated leukocytes or to quench those oxidants once they are formed by enhancing the antioxidant screen in the lungs. Recent preliminary studies with cilomilast, phosphodiesterase 4 inhibitor, have shown some therapeutic benefit in patients with COPD [92]. The mechanism by which such drugs may act is by increasing cAMP, which decreases neutrophil activation. In particular, the release of ROS by neutrophils may be decreased, since increasing cAMP blocks the assembly of NADPH oxidase [93]. In vitro studies have shown that Cilomilast can indeed decrease ROS [94].

There are various options to enhance the lung antioxidant screen. One approach would be to use specific spin traps, such as $\alpha$-phenyl-N-tert-butyl nitrone, to react directly with reactive oxygen and reactive nitrogen species at the site of inflammation. However, considerable work is needed to demonstrate the efficacy of such drugs in vivo. Inhibitors that have a double action, such as the inhibition of lipid peroxidation and quenching radicals, could be developed [95]. Another approach could be the molecular manipulation of antioxidant genes, such as GSH peroxidase or genes involved in the synthesis of GSH, such as $\gamma$ - glutamylcysteine synthetase, or by developing molecules with activity similar to these antioxidant enzymes.

Several classes of low molecular weight antioxidant mimetics have been produced with high rate constants for enzymatic scavenging of free-radical species.

Recent animal studies have shown that recombinant SOD treatment can prevent the neutrophil influx to the airspaces and IL-8 release induced by cigarette smoking through a mechanism involving down regulation of NF- $\mathrm{B}$ [86].

One of the low molecular weight mimetics of SOD has recently been shown to prevent the formation of emphysema in response to VEGF receptor blockade [96]. A further SOD mimetic of the manganoporphyrin class has also been shown in an animal model to significantly reduce the inflammation and squamous metaplasia induced by tobacco smoke [97]. Other strategies for reducing oxidative stress, such as the use of inducible nitric oxide synthase inhibitors to prevent the formation of peroxynitrite, could also be effective in preventing airway and lung inflammation.

This holds great promise if compounds can be developed with antioxidant enzyme properties that may be able to act as novel anti-inflammatory drugs by regulating the molecular events in lung inflammation.

A further approach would simply be to administer antioxidant therapy. This has been attempted in cigarette smokers using various antioxidants, such as vitamin C and vitamin E [98100]. The results of these studies have been rather disappointing, although the antioxidant vitamin $\mathrm{E}$ has been shown to reduce oxidative stress in patients with COPD [101]. Attempts to supplement lung GSH have been made using GSH or its precursors [102]. GSH itself is not efficiently transported into most animal cells and an excess of GSH may be a source of the thionyl radical under conditions of oxidative stress [103] Nebulised GSH has also been used therapeutically, but this has been shown to induce bronchial hyperreactivity [104].

The thiol cysteine is the rate-limiting amino acid in GSH synthesis [105]. Cysteine administration is not possible, since it is oxidised to cystine, which is neurotoxic [105]. The cysteinedonating compound $\mathrm{N}$-acetylcysteine (NAC) acts as a cellular precursor of GSH and is de-acetylated in the gut to cysteine following oral administration. It reduces disulphide bonds and has the potential to interact directly with oxidants. The use of NAC in an attempt to enhance GSH in patients with COPD has met with varying success $[106,107]$. NAC, given orally in low doses of $600 \mathrm{mgs}$ per day to normal subjects, results in very low levels of NAC in the plasma for up to $2 \mathrm{~h}$ after administration [108]. After 5 days of NAC $600 \mathrm{mg}$ three times daily, there was a significant increase in plasma GSH levels; however, there was no associated significant rise in BAL GSH or in lung tissue [109]. These data seem to imply that producing a sustained increase in lung GSH is difficult using NAC in subjects who are not already depleted of GSH.

Recent meta-analyses of the effects of NAC on exacerbations of COPD have shown positive effects $[109,110]$, but this was not reflected in a recent randomised controlled trial of NAC in 
COPD patients, although there appeared to be some effect on exacerbations in a subgroup of patients who were not taking inhaled corticosteroids [111]. A study of N-isobutyrylcysteine, a derivative of $\mathrm{N}$-acetylcysteine, also failed to reduce exacerbation rates in patients with COPD [112].

$\mathrm{N}$-acystelyn (NAL) is a lysine salt of NAC. It is also a mucolytic and oxidant thiol compound, which in contrast to NAC, which is acidic, has a neutral pH. NAL can be aerosolised into the lung without causing significant side effects. Studies comparing the effects of NAL and NAC found that both drugs enhanced intracellular GSH in alveolar epithelial cells [113] and inhibited $\mathrm{H}_{2} \mathrm{O}_{2}$ and $\mathrm{O}_{2}^{-}$anion release from neutrophils harvested from peripheral blood from smokers and patients with COPD [114].

Molecular regulation of glutathione synthesis, by targeting $\gamma$ glutamylcysteine synthetase, has promise as a means of treating oxidant mediated injury in the lungs. Recent work by MANNA et al. [115] has shown that recombinant $\gamma$-glutamylcysteine synthetase in rat hepatoma cells completely protected against the tumour necrosis factor alpha-induced activation of nuclear factor- $\mathrm{\kappa B}$, activator protein-1 and the apoptosis/inflammatory process [115]. Cellular glutathione may be increased by increasing $\gamma$-glutamylcysteine synthetase activity, which may be possible by gene transfer techniques, although this would be an expensive treatment that may not be considered for a condition such as chronic obstructive pulmonary disease. However, knowledge of how $\gamma$-glutamylcysteine synthetase is regulated may allow the development of other compounds that may act to enhance glutathione.

\section{REFERENCES}

1 Halliwell B. Antioxidants in human health and disease. Annu Rev Nutr 1996; 16: 33-50.

2 MacNee W. Oxidants/antioxidants and COPD. Chest 2000; 117: Suppl. 1, 303S-317S.

3 Rahman I, MacNee W. Role of transcription factors in inflammatory lung diseases. Thorax 1998; 53: 601612.

4 Agusti AG. Systemic effects of chronic obstructive pulmonary disease. Novartis Found Symp 2001; 234: 242-249.

5 Langen RC, Korn SH, Wouters EF. ROS in the local and systemic pathogenesis of COPD. Free Radic Biol Med 2003; 35: 226-235.

6 Pryor WA, Stone K. Oxidants in cigarette smoke. Radicals, hydrogen peroxide, peroxynitrate, and peroxynitrite. Ann N Y Acad Sci 1993; 686: 12-27.

7 Halliwell B, Gutteridge JM. Free radicals in biology and medicine. 3rd Edn. Oxford, Oxford University Press, 1999.

8 MacNee W, Donaldson K. Environmental factors in COPD. Voelkel NF, MacNee W, eds. Chronic Obstructive Lung Disease. London, BC Decker, 2002; pp. $145-160$.

9 Quinlan GJ, Lamb NJ, Tilley R, Evans TW, Gutteridge JM. Plasma hypoxanthine levels in ARDS: implications for oxidative stress, morbidity, and mortality. Am J Respir Crit Care Med 1997; 155: 479-484.
10 Goeptar AR, Scheerens H, Vermeulen NP. Oxygen and xenobiotic reductase activities of cytochrome P450. Crit Rev Toxicol 1995; 25: 25-65.

11 Halliwell B, Gutteridge JM. Role of free radicals and catalytic metal ions in human disease: an overview. Methods Enzymol 1990; 186: 1-85.

12 Van DV, O'Neill CA, Cross CE, et al. Determination of low-molecular-mass antioxidant concentrations in human respiratory tract lining fluids. Am J Physiol 1999; 276: L289-L296.

13 Reynolds HY, Newball HH. Analysis of proteins and respiratory cells obtained from human lungs by bronchial lavage. J Lab Clin Med 1974; 84: 559-573.

14 Crapo JD, Oury T, Rabouille C, Slot JW, Chang LY. Copper, zinc superoxide dismutase is primarily a cytosolic protein in human cells. Proc Natl Acad Sci USA 1992; 9: 10405-10409.

15 Weisiger RA, Fridovich I. Mitochondrial superoxide simutase. Site of synthesis and intramitochondrial localization. J Biol Chem 1973; 248: 4793-4796.

16 Weisiger RA, Fridovich I. Superoxide dismutase. Organelle specificity. J Biol Chem 1973; 248: 3582-3592.

17 Marklund SL. Human copper-containing superoxide dismutase of high molecular weight. Proc Natl Acad Sci USA 1982; 79: 7634-7638.

18 Chang LY, Kang BH, Slot JW, Vincent R, Crapo JD. Immunocytochemical localization of the sites of superoxide dismutase induction by hyperoxia in rat lungs. $L a b$ Invest 1995; 73: 29-39.

19 Coursin DB, Cihla HP, Oberley TD, Oberley LW. Immunolocalization of antioxidant enzymes and isozymes of glutathione S-transferase in normal rat lung. Am J Physiol 1992; 263: L679-L691.

20 Clyde BL, Chang LY, Auten RL, Ho YS, Crapo JD. Distribution of manganese superoxide dismutase mRNA in normal and hyperoxic rat lung. Am J Respir Cell Mol Biol 1993; 8: 530-537.

21 Gilks CB, Price K, Wright JL, Churg A. Antioxidant gene expression in rat lung after exposure to cigarette smoke. Am J Pathol 1998; 152: 269-278.

22 Sadek CM, Jimenez A, Damdimopoulos AE, et al. Characterization of human thioredoxin-like 2. A novel microtubule-binding thioredoxin expressed predominantly in the cilia of lung airway epithelium and spermatid manchette and axoneme. J Biol Chem 2003; 278: 13133-13142.

23 Gromer S, Urig S, Becker K. The thioredoxin systemfrom science to clinic. Med Res Rev 2004; 24: 40-89.

24 Nordberg J, Arner ES. Reactive oxygen species, antioxidants, and the mammalian thioredoxin system. Free Radic Biol Med 2001; 31: 1287-1312.

25 Cantin AM, North SL, Hubbard RC, Crystal RG. Normal alveolar epithelial lining fluid contains high levels of glutathione. J Appl Physiol 1987; 63: 152-157.

26 Hoidal JR, Fox RB, LeMarbe PA, Perri R, Repine JE. Altered oxidative metabolic responses in vitro of alveolar macrophages from asymptomatic cigarette smokers. Am Rev Respir Dis 1981; 123: 85-89.

27 Dekhuijzen PN, Aben KK, Dekker I, et al. Increased exhalation of hydrogen peroxide in patients with stable 
and unstable chronic obstructive pulmonary disease. Am J Respir Crit Care Med 1996; 154: 813-816.

28 Nowak D, Kasielski M, Pietras T, Bialasiewicz P, Antczak A. Cigarette smoking does not increase hydrogen peroxide levels in expired breath condensate of patients with stable COPD. Monaldi Arch Chest Dis 1998; 53: 268-273.

29 Heunks LM, Vina J, van Herwaarden CL, Folgering HT, Gimeno A, Dekhuijzen PN. Xanthine oxidase is involved in exercise-induced oxidative stress in chronic obstructive pulmonary disease. Am J Physiol 1999; 277: R1697-R1704.

30 Pinamonti S, Muzzoli M, Chicca MC, et al. Xanthine oxidase activity in bronchoalveolar lavage fluid from patients with chronic obstructive pulmonary disease. Free Radic Biol Med 1996; 21: 147-155.

31 Delen FM, Sippel JM, Osborne ML, Law S, Thukkani N, Holden WE. Increased exhaled nitric oxide in chronic bronchitis: comparison with asthma and COPD. Chest 2000; 117: 695-701.

32 Maziak W, Loukides S, Culpitt S, Sullivan P, Kharitonov SA, Barnes PJ. Exhaled nitric oxide in chronic obstructive pulmonary disease. Am J Respir Crit Care Med 1998; 157: 998-1002.

33 Corradi M, Majori M, Cacciani GC, Consigli GF, de'Munari E, Pesci A. Increased exhaled nitric oxide in patients with stable chronic obstructive pulmonary disease. Thorax 1999; 54: 572-575.

34 Rutgers SR, van der Mark TW, Coers W, et al. Markers of nitric oxide metabolism in sputum and exhaled air are not increased in chronic obstructive pulmonary disease. Thorax 1999; 54: 576-580.

35 Clini E, Bianchi L, Pagani M, Ambrosino N. Endogenous nitric oxide in patients with stable COPD: correlates with severity of disease. Thorax 1998; 53: 881-883.

36 Corradi M, Montuschi P, Donnelly LE, Pesci A, Kharitonov SA, Barnes PJ. Increased nitrosothiols in exhaled breath condensate in inflammatory airway diseases. Am J Respir Crit Care Med 2001; 163: 854-858.

37 Petruzzelli S, Puntoni R, Mimotti P, et al. Plasma 3nitrotyrosine in cigarette smokers. Am J Respir Crit Care Med 1997; 156: 1902-1907.

38 Ichinose M, Sugiura H, Yamagata S, Koarai A, Shirato K. Increase in reactive nitrogen species production in chronic obstructive pulmonary disease airways. Am J Respir Crit Care Med 2000; 162: 701-706.

39 Paredi P, Kharitonov SA, Leak D, Ward S, Cramer D, Barnes PJ. Exhaled ethane, a marker of lipid peroxidation, is elevated in chronic obstructive pulmonary disease. Am J Respir Crit Care Med 2000; 162: 369-373.

40 Nowak D, Kasielski M, Antczak A, Pietras T, Bialasiewicz P. Increased content of thiobarbituric acidreactive substances and hydrogen peroxide in the expired breath condensate of patients with stable chronic obstructive pulmonary disease: no significant effect of cigarette smoking. Respir Med 1999; 93: 389-396.

41 Tsukagoshi H, Shimizu Y, Iwamae S, et al. Evidence of oxidative stress in asthma and COPD: potential inhibitory effect of theophylline. Respir Med 2000; 94: 584-588.

42 Corradi M, Rubinstein I, Andreoli R, et al. Aldehydes in exhaled breath condensate of patients with chronic obstructive pulmonary disease. Am I Respir Crit Care Med 2003; 167: 1380-1386.

43 Montuschi P, Collins JV, Ciabattoni G, et al. Exhaled 8isoprostane as an in vivo biomarker of lung oxidative stress in patients with COPD and healthy smokers. Am J Respir Crit Care Med 2000; 162: 1175-1177.

44 Frangulyan R, Anderson D, Drost E, Hill A, MacNee W. Exhaled markers of inflammation in breath condensate in patients with bronchiectasis and COPD. Thorax 2003; 58: Suppl. 3, S116.

45 Morrow JD, Frei B, Longmire AW, et al. Increase in circulating products of lipid peroxidation (F2isoprostanes) in smokers. Smoking as a cause of oxidative damage. $N$ Engl J Med 1995; 332: 1198-1203.

46 Pratico D, Basili S, Vieri M, Cordova C, Violi F, FitzGerald GA. Chronic obstructive pulmonary disease is associated with an increase in urinary levels of isoprostane F2alpha-III, an index of oxidant stress. Am J Respir Crit Care Med 1998; 158: 1709-1714.

47 Habib MP, Clements NC, Garewal HS. Cigarette smoking and ethane exhalation in humans. Am J Respir Crit Care Med 1995; 151: 1368-1372.

48 Rahman I, van Schadewijk AA, Crowther AJ, et al. 4Hydroxy-2-nonenal, a specific lipid peroxidation product, is elevated in lungs of patients with chronic obstructive pulmonary disease. Am J Respir Crit Care Med 2002; 166: 490-495.

49 Rahman I, Morrison D, Donaldson K, MacNee W. Systemic oxidative stress in asthma, COPD, and smokers. Am J Respir Crit Care Med 1996; 154: 1055-1060.

50 Donaldson K, Brown DM, Mitchell C, et al. Free radical activity of PM10: iron-mediated generation of hydroxyl radicals. Environ Health Perspect 1997; 105: Suppl. 5, 1285-1289.

51 Wouters EF, Creutzberg EC, Schols AM. Systemic effects in COPD. Chest 2002; 121: 127S-130S.

52 Morrison D, Rahman I, Lannan S, MacNee W. Epithelial permeability, inflammation, and oxidant stress in the air spaces of smokers. Am J Respir Crit Care Med 1999; 159: 473-479.

53 Schwartz J, Weiss ST. Relationship between dietary vitamin $C$ intake and pulmonary function in the First National Health and Nutrition Examination Survey (NHANES I). Am J Clin Nutr 1994; 59: 110-114.

54 Schwartz J, Weiss ST. Dietary factors and their relation to respiratory symptoms. The Second National Health and Nutrition Examination Survey. Am J Epidemiol 1990; 132: 67-76.

$55 \mathrm{Hu} \mathrm{G}$, Cassano PA. Antioxidant nutrients and pulmonary function: the Third National Health and Nutrition Examination Survey (NHANES III). Am J Epidemiol 2000; 151: 975-981.

56 Tabak C, Smit HA, Heederik D, Ocke MC, Kromhout D. Diet and chronic obstructive pulmonary disease: independent beneficial effects of fruits, whole grains, and alcohol (the MORGEN study). Clin Exp Allergy 2001; 31: 747-755.

57 Miedema I, Feskens EJ, Heederik D, Kromhout D. Dietary determinants of long-term incidence of chronic nonspecific lung diseases. The Zutphen Study. Am J Epidemiol 1993; 138: 37-45. 
58 Strachan DP, Cox BD, Erzinclioglu SW, Walters DE, Whichelow MJ. Ventilatory function and winter fresh fruit consumption in a random sample of British adults. Thorax 1991; 46: 624-629.

59 Tabak C, Feskens EJ, Heederik D, Kromhout D, Menotti A, Blackburn HW. Fruit and fish consumption: a possible explanation for population differences in COPD mortality (The Seven Countries Study). Eur J Clin Nutr 1998; 52: 819-825.

60 Rahman I, Li XY, Donaldson K, Harrison DJ, MacNee W. Glutathione homeostasis in alveolar epithelial cells in vitro and lung in vivo under oxidative stress. Am J Physiol 1995; 269: L285-L292.

61 Rahman I, Smith CA, Lawson MF, Harrison DJ, MacNee W. Induction of gamma-glutamylcysteine synthetase by cigarette smoke is associated with AP-1 in human alveolar epithelial cells. FEBS Lett 1996; 396: 21-25.

62 Rahman I, Antonicelli F, MacNee W. Molecular mechanism of the regulation of glutathione synthesis by tumor necrosis factor-alpha and dexamethasone in human alveolar epithelial cells. J Biol Chem 1999; 274: 5088-5096.

63 Rahman I, Smith CA, Antonicelli F, MacNee W. Characterisation of gamma-glutamylcysteine synthetaseheavy subunit promoter: a critical role for AP-1. FEBS Lett 1998; 427: 129-133.

64 MacNee W. Oxidative stress and lung inflammation in airways disease. Eur J Pharmacol 2001; 429: 195-207.

65 Janoff A, Carp H, Laurent P, Raju L. The role of oxidative processes in emphysema. Am Rev Respir Dis 1983; 127: S31-S38.

66 Stockley RA. Proteases and antiproteases. Novartis Found Symp 2001; 234: 189-199.

67 Bieth JG. The antielastase screen of the lower respiratory tract. Eur J Respir Dis 1985; 139: Suppl., 57-61.

68 Evans MD, Pryor WA. Damage to human alpha-1proteinase inhibitor by aqueous cigarette tar extracts and the formation of methionine sulfoxide. Chem Res Toxicol 1992; 5: 654-660.

69 Abboud RT, Fera T, Richter A, Tabona MZ, Johal S. Acute effect of smoking on the functional activity of alpha1protease inhibitor in bronchoalveolar lavage fluid. Am Rev Respir Dis 1985; 131: 79-85.

70 Adler KB, Holden-Stauffer WJ, Repine JE. Oxygen metabolites stimulate release of high-molecular-weight glycoconjugates by cell and organ cultures of rodent respiratory epithelium via an arachidonic aciddependent mechanism. J Clin Invest 1990; 85: 75-85.

71 Nadel JA. Role of epidermal growth factor receptor activation in regulating mucin synthesis. Respir Res 2001; 2: 85-89.

72 Feldman C, Anderson R, Kanthakumar K, Vargas A, Cole PJ, Wilson R. Oxidant-mediated ciliary dysfunction in human respiratory epithelium. Free Radic Biol Med 1994; 17: 1-10.

73 Rusznak C, Mills PR, Devalia JL, Sapsford RJ, Davies RJ, Lozewicz S. Effect of cigarette smoke on the permeability and IL-1beta and sICAM-1 release from cultured human bronchial epithelial cells of never-smokers, smokers, and patients with chronic obstructive pulmonary disease. Am J Respir Cell Mol Biol 2000; 23: 530-536.
$74 \mathrm{Li}$ XY, Donaldson K, Rahman I, MacNee W. An investigation of the role of glutathione in increased epithelial permeability induced by cigarette smoke in vivo and in vitro. Am J Respir Crit Care Med 1994; 149: 1518-1525.

75 Li XY, Rahman I, Donaldson K, MacNee W. Mechanisms of cigarette smoke induced increased airspace permeability. Thorax 1996; 51: 465-471.

76 Di Stefano A, Caramori G, Ricciardolo FL, Capelli A, Adcock IM, Donner CF. Cellular and molecular mechanisms in chronic obstructive pulmonary disease: an overview. Clin Exp Allergy 2004; 34: 1156-1167.

77 Rahman I. Oxidative stress, transcription factors and chromatin remodelling in lung inflammation. Biochem Pharmacol 2002; 64: 935-942.

78 Di Stefano A, Caramori G, Oates $T$, et al. Increased expression of nuclear factor-kappaB in bronchial biopsies from smokers and patients with COPD. Eur Respir J 2002; 20: 556-563.

79 MacNee W, Rahman I. Is oxidative stress central to the pathogenesis of chronic obstructive pulmonary disease? Trends Mol Med 2001; 7: 55-62.

80 Janssen-Heininger YM, Macara I, Mossman BT. Cooperativity between oxidants and tumor necrosis factor in the activation of nuclear factor (NF)-kappaB: requirement of Ras/mitogen-activated protein kinases in the activation of NF-kappaB by oxidants. Am J Respir Cell Mol Biol 1999; 20: 942-952.

81 Flohe L, Brigelius-Flohe R, Saliou C, Traber MG, Packer L. Redox regulation of NF-kappa B activation. Free Radic Biol Med 1997; 22: 1115-1126.

82 Parmentier M, Hirani N, Rahman I, Donaldson K, MacNee W, Antonicelli F. Regulation of lipopolysaccharide-mediated interleukin-1beta release by N-acetylcysteine in THP-1 cells. Eur Respir J 2000; 16: 933-939.

83 Jimenez LA, Thompson J, Brown DA, et al. Activation of NF-kappaB by $\mathrm{PM}(10)$ occurs via an iron-mediated mechanism in the absence of IkappaB degradation. Toxicol Appl Pharmacol 2000; 166: 101-110.

84 Szulakowski P, Drost E, Jimenez LA, et al. Role of histone acetylation in transcriptional regulation and promotion of inflammatory process in patients with chronic obstructive pulmonary disease. Am J Respir Crit Care Med 2004; 169: A275.

85 Crowther AJ, Rahman I, Antonicelli F, Jimenez LA, Salter D, MacNee W. Oxidative stress and transcription factors AP-1 and NF-B in human lung tissue. Am J Respir Crit Care Med 1999; 159: A816.

86 Nishikawa M, Kakemizu N, Ito T, et al. Superoxide mediates cigarette smoke-induced infiltration of neutrophils into the airways through nuclear factor-kappaB activation and IL-8 mRNA expression in guinea pigs in vivo. Am J Respir Cell Mol Biol 1999; 20: 189-198.

87 Marwick JA, Kirkham P, Stevenson CS, et al. Cigarette smoke alters chromatin remodelling and induces proinflammatory genes in rat lungs. Am J Respir Cell Mol Biol 2004; 31: 633-642.

88 Tuder RM, Petrache I, Elias JA, Voelkel NF, Henson PM. Apoptosis and emphysema: the missing link. Am J Respir Cell Mol Biol 2003; 28: 551-554. 
89 Kasahara Y, Tuder RM, Cool CD, Lynch DA, Flores SC, Voelkel NF. Endothelial cell death and decreased expression of vascular endothelial growth factor and vascular endothelial growth factor receptor 2 in emphysema. Am J Respir Crit Care Med 2001; 163: 737-744.

90 Tuder RM, Zhen L, Cho CY, et al. Oxidative stress and apoptosis interact and cause emphysema due to vascular endothelial growth factor receptor blockade. Am J Respir Cell Mol Biol 2003; 29: 88-97.

91 Agusti A, Morla M, Sauleda J, Saus C, Busquets X. NFkappaB activation and iNOS upregulation in skeletal muscle of patients with COPD and low body weight. Thorax 2004; 59: 483-487.

92 Compton CH, Gubb J, Cedar E, et al. SB 207499, a second generation oral PDE4 inhibitor, first demonstration of efficacy in patients with COPD. Eur Respir J 1999; 14: 281s.

93 Torphy TJ. Phosphodiesterase isozymes: molecular targets for novel antiasthma agents. Am J Respir Crit Care Med 1998; 157: 351-370.

94 Drost E, Ouziaux L, Donaldson K, MacNee W. Cilomilast, a second generation phosphodiesterase 4 inhibitor, in combination with PGE2 attenuates fMLP, IL-8 and cigarette smoke-induced effects on the mechanical and functional properties of neutrophils. Eur Respir J 2001; 18 : Suppl. 33, 161S.

95 Chabrier PE, Auguet M, Spinnewyn B, et al. BN 80933, a dual inhibitor of neuronal nitric oxide synthase and lipid peroxidation: a promising neuroprotective strategy. Proc Natl Acad Sci USA 1999; 96: 10824-10829.

96 Tuder RM, Zhen L, Cho CY, et al. Oxidative stress and apoptosis interact and cause emphysema due to vascular endothelial growth factor receptor blockade. Am J Respir Cell Mol Biol 2003; 29: 88-97.

97 Smith KR, Uyeminami DL, Kodavanti UP, Crapo JD, Chang LY, Pinkerton KE. Inhibition of tobacco smokeinduced lung inflammation by a catalytic antioxidant. Free Radic Biol Med 2002; 33: 1106-1114.

98 Romieu I, Trenga C. Diet and obstructive lung diseases. Epidemiol Rev 2001; 23: 268-287.

99 Daga MK, Chhabra R, Sharma B, Mishra TK. Effects of exogenous vitamin $\mathrm{E}$ supplementation on the levels of oxidants and antioxidants in chronic obstructive pulmonary disease. J Biosci 2003; 28: 7-11.

100 Smit HA, Grievink L, Tabak C. Dietary influences on chronic obstructive lung disease and asthma: a review of the epidemiological evidence. Proc Nutr Soc 1999; 58: 309-319.

101 Steinberg FM, Chait A. Antioxidant vitamin supplementation and lipid peroxidation in smokers. Am J Clin Nutr 1998; 68: 319-327.

102 MacNee W, Bridgeman MM, Marsden M, et al. The effects of $\mathrm{N}$-acetylcysteine and glutathione on smoke-induced changes in lung phagocytes and epithelial cells. Am J Med 1991; 91: Suppl. 3c, 60S-66S.

103 Ross D, Norbeck K, Moldeus P. The generation and subsequent fate of glutathionyl radicals in biological systems. J Biol Chem 1985; 260: 15028-15032.

104 Marrades RM, Roca J, Barbera JA, de Jover L, MacNee W, Rodriguez-Roisin R. Nebulized glutathione induces bronchoconstriction in patients with mild asthma. Am J Respir Crit Care Med 1997; 156: 425-430.

105 Meister A, Anderson ME. Glutathione. Annu Rev Biochem 1983; 52: 711-760.

106 Bridgeman MM, Marsden M, MacNee W, Flenley DC, Ryle AP. Cysteine and glutathione concentrations in plasma and bronchoalveolar lavage fluid after treatment with N-acetylcysteine. Thorax 1991; 46: 39-42.

107 Bridgeman MM, Marsden M, Selby C, Morrison D, MacNee W. Effect of $\mathrm{N}$-acetyl cysteine on the concentrations of thiols in plasma, bronchoalveolar lavage fluid, and lung tissue. Thorax 1994; 49: 670-675.

108 Drost EM, Selby C, Lannan S, Lowe GD, MacNee W. Changes in neutrophil deformability following in vitro smoke exposure: mechanism and protection. Am J Respir Cell Mol Biol 1992; 6: 287-295.

109 Stey C, Steurer J, Bachmann S, Medici TC, Tramer MR. The effect of oral $\mathrm{N}$-acetylcysteine in chronic bronchitis: a quantitative systematic review. Eur Respir J 2000; 16: 253-262.

110 Grandjean EM, Berthet P, Ruffmann R, Leuenberger P. Efficacy of oral long-term $\mathrm{N}$-acetylcysteine in chronic bronchopulmonary disease: a meta-analysis of published double-blind, placebo-controlled clinical trials. Clin Ther 2000; 22: 209-221.

111 Decramer M, Rütten-Von Molken M, Dekhuijzen RPN, et al. Effects of NAC on outcome variables in COPD patients. Eur Respir J 2004; 24: Suppl. 48, 14s.

112 Ekberg-Jansson A, Larson M, MacNee W, et al. Nisolutyculcysteine, a donor of systemic thiols, does not reduce the exacerbation rate in chronic bronchitis. Eur Respir J 1999; 13: 829-834.

113 Gillissen A, Jaworska M, Orth M, et al. Nacystelyn, a novel lysine salt of $\mathrm{N}$-acetylcysteine, to augment cellular antioxidant defence in vitro. Respir Med 1997; 91: 159-168.

114 Nagy AM, Vanderbist F, Parij N, Maes P, Fondu P, Neve J. Effect of the mucoactive drug nacystelyn on the respiratory burst of human blood polymorphonuclear neutrophils. Pulm Pharmacol Ther 1997; 10: 287-292.

115 Manna SK, Kuo MT, Aggarwal BB. Overexpression of gamma-glutamylcysteine synthetase suppresses tumor necrosis factor-induced apoptosis and activation of nuclear transcription factor-kappa B and activator protein-1. Oncogene 1999; 18: 4371-4382. 